\title{
ASSESSMENT OF THE CURRENT GERIATRIC PHARMACEUTICAL CARE IN THE UNITED ARAB EMIRATES
}

\author{
OSAMA MOHAMED IBRAHIM ${ }^{1,2 *}$, RANA IBRAHIM ${ }^{1}$ \\ ${ }^{1}$ Department of Pharmacy Practice and Pharmacotherapeutics, College of Pharmacy, University of Sharjah, Sharjah, United Arab Emirates. \\ ${ }^{2}$ Department of Clinical Pharmacy, Faculty of Pharmacy, Cairo University, Giza, Egypt. Email: oibrahim@sharjah.ac.ae
}

Received: 10 May 2019, Revised and Accepted: 26 June 2019

\section{ABSTRACT}

Objectives: The primary goal of this study is to assess the current geriatric pharmaceutical care and patient satisfaction among elderly patient. Another aim is to increase the awareness among pharmacists in providing better guidelines for proper geriatric pharmaceutical care in the United Arab Emirates (UAE).

Methods: A pilot observational study was done through the dissemination of cross-sectional surveys among pharmacists and geriatrics in the Emirates of Abu Dhabi, Dubai, and Sharjah. Three hundred and eight pharmacists and 110 geriatric patients were randomly selected to participate in the study.

Results: Among pharmacists participating in the study, 32.1\% were from Abu Dhabi, 37.6\% from Dubai, and 30.1\% from Sharjah. Geriatric patients who participated from Abu Dhabi were 30.0\%, 38.1\% were from Dubai, and 31.8\% were from Sharjah. Geriatrics level of satisfaction was higher in Abu Dhabi compared to Sharjah and Dubai ( $\mathrm{p}=0.0005)$. Pharmacists in Sharjah and Dubai had higher interest in taking special courses on how to deal with elderly patients compared to pharmacists in Abu Dhabi $(\mathrm{p}<0.0001)$.

Conclusions: Geriatrics satisfaction toward pharmaceutical care is not the same in all Emirates of the UAE. This calls for implementing diverse measures such as providing training courses for pharmacists specialized in geriatrics care, which aims to provide a high-quality pharmaceutical care to all geriatrics in the UAE.

Keywords: Pharmacy, Geriatrics, Health status, Pharmaceutical care.

(C) 2019 The Authors. Published by Innovare Academic Sciences Pvt Ltd. This is an open access article under the CC BY license (http://creativecommons. org/licenses/by/4. 0/) DOI: http://dx.doi.org/10.22159/ajpcr.2019.v12i8.34045

\section{INTRODUCTION}

Medication mismanagement, particularly in the elderly, is a constant, crucial, and life-threatening issue that is attributed to several factors including inadequate pharmaceutical care. Geriatrics is patients who are 60 years or older according to the United Nations classifications [1]. In 2010 , there were nearly 40,000 people over the age of 60 in the United Arab Emirates (UAE). The Ministry of Health is expecting this figure to increase by $20 \%$ around the year 2020 . The UAEs aging population and rapid social change are putting health and well-being of the elderly at risk $[1,2]$.

According to the American Society of Health-System Pharmacists, pharmaceutical care is the responsible, direct provision of medicationrelated care with the rationale of achieving outcomes that improve a patient's quality of life [2]; while the World Health Organization defined pharmaceutical care as a philosophy of practice, in which the patient is the primary beneficiary of the pharmacist's actions. Pharmaceutical care focuses on the ethics, attitudes, commitments, behaviors, concerns, knowledge, functions, responsibilities, and skills of the pharmacist with the aim of achieving therapeutic outcomes toward patient health and quality of life [3].

As a person grows older, pharmacokinetics and pharmacodynamics alterations occur to his/her bodily functions. Medications usually increase in number due to increased diseases and dysfunctions, leading to a higher chance of drug-drug interactions, adverse drug reactions, noncompliance, and inadequate response to therapy $[4,5]$.

According to Dubai health authority, the five leading causes of death in the geriatric population were ischemic heart disease (23.4\%), neoplasm
(20.5\%), cerebrovascular diseases $(7.8 \%)$, septicemia $(7.0 \%)$, and renal failure (6.2\%) [6].

There are number of factors in geriatric population which contribute to the increased risk of developing a drug-related problem and therefore call for the need to individualize pharmaceutical care. For instance, $25 \%$ of geriatrics takes at least three drugs causing them to have increased risk of poor compliance. The $3^{\text {rd }}$ National Health and Nutrition Examination Survey study among nursing home residents found that approximately $30 \%$ of patients age 75 or older with two or more chronic conditions take at least five prescription drugs regularly [7]. This number of medications may be as high or even more.

Furthermore, the elderly have several diseases and comorbidities that require treatment with several drugs increasing the risk of drug-drug interactions. For example, the use of thiazide diuretics and insulin concomitantly reduces the effectiveness of insulin $[8,9]$.

On the other hand, polypharmacy is a reoccurring issue defined as the use of multiple medications by a patient. Polypharmacy is a significant concern in older people who, compared to younger individuals, tend to have more disease conditions, for which therapies are prescribed. Older individuals are at greater risk for adverse drug events due to metabolic changes; this risk is complicated by increasing numbers of drugs used $[10,11]$. Polypharmacy increases the potential for drugdrug interactions, augmenting the possibility of "prescribing cascades" which occurs when an adverse drug event is misinterpreted as a new medical condition and additional drug therapy is then prescribed to treat this medical condition [12]. Minimizing polypharmacy requires periodic evaluation of patient's drug regimen which is an essential component of medical care for an older person [13]. The role of the 
pharmacists in the reduction of polypharmacy in the elderly cannot be overemphasized.

When pharmacists counsel elderly patients, they should follow certain techniques and tools in counseling geriatrics to ensure optimum outcomes and adherence to medications. They must be able to identify drug-related problems, history of conditions, particularly gastrointestinal (GI), kidney, and liver, complete drug use, assess factors that may contribute to noncompliance, use strategies to maximize learning ability, and use key questions to enhance learning [14].

Pharmaceutical care programs developed and implemented by pharmacists have been found useful in improving the quality of care of both hospitalized and ambulatory patients with various diseases such as hypertension, asthma, dyslipidemia, and heart failure. This confirms the importance of geriatric pharmaceutical care, and thus, more light should be shed on it. The next step in the evolution of geriatric pharmaceutical care will be to improve the coordination of treatments. If pharmaceutical care is implemented, it will result in added value to drug therapy by making a constructive contribution to the safe and cost-effective use of drugs, leading to positive outcomes and improved health care [3].

The objective of this study is to assess the current pharmaceutical care and patient satisfaction among elderly patient. Another aim is to increase the awareness among pharmacists in providing better guidelines for proper geriatric pharmaceutical care in the UAE.

\section{METHODS}

A pilot observational study was done through the dissemination of crosssectional surveys among pharmacists and geriatrics in the Emirates of Abu Dhabi, Dubai, and Sharjah. Scientific literature about pharmaceutical care was collected as a building block for this study. Studies based on surveys were chosen to serve as a template for the design of the survey's questions. Two cross-sectional surveys, targeting pharmacists and the geriatric population, were compiled from previously validated surveys $[3,15,16]$ with minor modifications to make them convenient with the UAE practice setting. Moreover, surveys were distributed to 10 pharmacists and geriatrics for validation and recommendations before proceeding with the survey distribution. The pharmacists' survey was comprised of two parts, the first section contained questions related to the demographic characteristics and the second section assessed the pharmacist's knowledge in regard to the pharmaceutical care provided to the geriatrics population in the UAE. On the other hand, the geriatrics survey contained three parts; the first section included questions related to the demographic characteristics and the second section included questions about health conditions related to the elderly. The third section included questions about assessing the geriatrics satisfaction toward the pharmaceutical care offered in the UAE.

Before the study began, approval for distributing the questionnaires was obtained from University of Sharjah Research Ethics Committee.

Three hundred and eight pharmacists and 110 geriatric patients were randomly selected to participate in the study. Surveys were distributed manually to the participants. All data received from the participants were kept confidential and anonymous. Geriatrics included in the study sample was those aged 60 years old and above. All geriatric patients included in the study were taking medications.

The data were analyzed statistically using the Statistical Package for the Social Sciences "SPSS" Version 20 to determine if there are any statistically significant differences in pharmaceutical care between the Emirates of Abu Dhabi, Dubai, and Sharjah.

\section{RESULTS}

\section{Sample demographics}

Demographics with descriptive statistics of pharmacists and geriatrics who participated in the study are displayed in Table 1.

\section{Analysis of pharmacist survey questions}

The total number of pharmacists who participated in the study was 308. Of the total sample, $82.4 \%$ of pharmacists reported counseling to elderly patients more than counseling to younger patients. However, $17.5 \%$ of pharmacists counseled elderly patients just as younger patients. Moreover, $73.0 \%$ of pharmacists stated that elderly patients found it hard to understand their instructions. Table 2 shows counseling questions directed to pharmacists.

Fig. 1 shows the names of medications that pharmacists dispense with caution to elderly population.

The results of the study reveal that $29 \%$ of participants described their relationship with pharmacists as excellent and only $20 \%$ of the geriatric patients stated that the pharmacists talk with them about the medications every time they dispense the medicine. It was also revealed that $32.7 \%$ of the study population are satisfied with the level of pharmaceutical care offered to them. On the other hand, $81.8 \%$ of the geriatrics stated that pharmacists are using simple language in counseling them and $40.9 \%$ confirmed that pharmacists are assisting them to adhere to the medications. About $54.5 \%$ stated that they do not need any more counseling on the medications they are currently using.

Table 1: Patient's demographics

\begin{tabular}{ll}
\hline Characteristics & Results \\
\hline Geriatrics & \\
\% male & $52 \%$ \\
Average age (years) \pm SD & $79 \pm 2.6$ \\
Average number of medications \pm SD & $4.3 \pm 1.1$ \\
Average number of comorbid diseases \pm SD & $3.2 \pm 0.75$ \\
Most common comorbidities (\%) & \\
Diabetes & 50 \\
Musculoskeletal & 29.8 \\
Cardiovascular & 29 \\
Dementia & 22.6 \\
GIT problems & 22.6 \\
Emirate (\%) & \\
Abu Dhabi & 30.0 \\
Dubai & 38.1 \\
Sharjah & 31.8 \\
\% residents in long-term care facilities & 48 \\
Pharmacists (\%) & \\
Emirate & \\
Abu Dhabi & 32.1 \\
Dubai & 37.6 \\
Sharjah & 30.1 \\
Degree & 80.1 \\
Bachelor & 10.4 \\
Master & 8.2 \\
Pharm D & \\
\hline SD: Standard deviation & \\
\hline
\end{tabular}

Table 2: Counseling elderly patients

\begin{tabular}{|c|c|}
\hline Questions & Yes, n (\%) \\
\hline $\begin{array}{l}\text { Do you counsel elderly patients more than } \\
\text { you would counsel young patients? }\end{array}$ & $254(82.4)$ \\
\hline $\begin{array}{l}\text { Do you think elderly patients find it hard to } \\
\text { understand your instructions? }\end{array}$ & $225(73.0)$ \\
\hline $\begin{array}{l}\text { Do you offer special counseling techniques } \\
\text { for elderly patients? }\end{array}$ & $248(80.5)$ \\
\hline $\begin{array}{l}\text { Do you maintain eye contact with your } \\
\text { patient? }\end{array}$ & 298 (96.7) \\
\hline $\begin{array}{l}\text { Do you give your patient the opportunity to } \\
\text { ask questions? }\end{array}$ & 306 (99.3) \\
\hline $\begin{array}{l}\text { Do you summarize the most important } \\
\text { points at the end? }\end{array}$ & 274 (88.9) \\
\hline
\end{tabular}


Fig. 2 shows the different adherence techniques that were offered by the pharmacists to the geriatric population.

When the geriatric patients were asked if they would listen to the pharmacist counseling when offered, about $19 \%$ stated that they would not listen for different reasons. The most common reason for refusing the counseling was using the medication for long time (56.7\%) followed by the answer that they can help themselves (33.3\%).

In pharmacists' survey, the results showed that majority of patients in Sharjah and Dubai (74.5\%) think that pharmacists should be more trained to deal with elderly patients. On the other hand, similar percentage from Abu Dhabi patients (78.6\%) responded that they need to take a special course about how to deal with geriatric patients $(\mathrm{p}=0.67)$.

In addition, the results indicated that pharmacists found elderly patients to be the most difficult group category to deal with, which was represented by $53.8 \%$ of the responses. Children, represented by $29.8 \%$ of the responses, were the second most difficult group category to deal with.

According to the study population, the most common chronic diseases affecting the elderly in the UAE were diabetes mellitus (50\%), musculoskeletal conditions (29.8\%), cardiovascular diseases (29.0\%), neurologic conditions (22.6\%), and GI problems (22.6\%).

Of the total geriatric sample, 51.8\% described their relationship with their pharmacist as "Moderate," 29.0\% described it as "Excellent," and $19 \%$ described it as "Poor."

Mainly, geriatrics from Abu Dhabi described their relationship with their pharmacists as "Excellent," while geriatrics from Dubai and Sharjah described it as "Moderate" and "Poor."

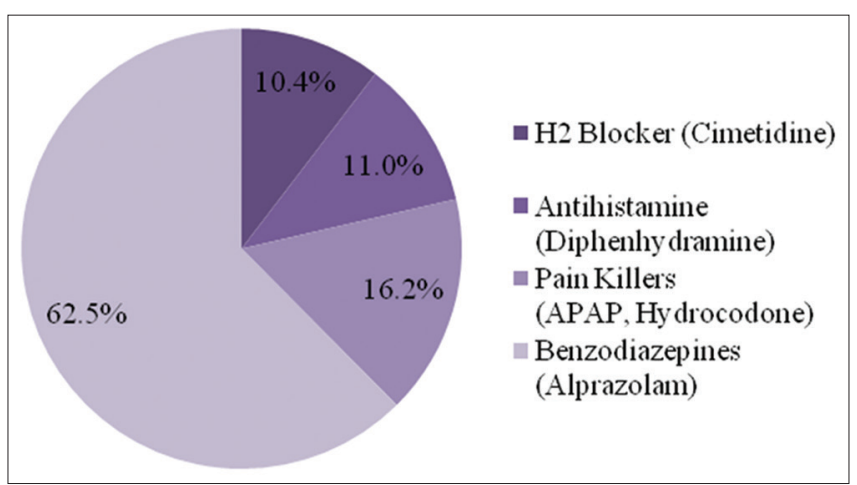

Fig. 1: Drugs dispensed cautiously by the pharmacists to the elderly
Moreover, results also showed that 50.9\% of geriatrics were talking to their pharmacists "occasionally" about their medications, $29.0 \%$ "never" talked to their pharmacists about their medications, and 20.0\% reported talking to their pharmacists "every time they see them."

Table 3 shows the different techniques used by pharmacists to improve elderly patients' adherence.

Results illustrated that $54.5 \%$ of geriatrics were satisfied by the time needed for counseling. Majority of geriatrics (90.9\%) reported that they would listen to their pharmacists while $19.5 \%$ stated that they would not have time to listen to pharmacist when offering them information about their medications.

\section{DISCUSSION}

The impact of family and social relationships among the elderly plays an important factor in health, for it provides emotional and physical support. In addition to that, family support has shown an increase of medication adherence in the elderly, which in result increases the quality of life $[15,16]$.

There are several health authorities in the UAE, and all of them aim to provide a high quality of health care to citizens. For this study, results of Abu Dhabi were compared to the results retrieved from Dubai and Sharjah. The study results showed that geriatrics' satisfaction toward the pharmaceutical care offered in the Emirate of Abu Dhabi was 63.6\%, while Dubai and Sharjah showed a satisfaction percentage of $27.2 \%$ only. There are many key factors that play a role in geriatrics' satisfaction toward the pharmaceutical care such as the elderly relationship with the pharmacist. About $90 \%$ of the elderly in the Emirate of Abu Dhabi described their relationship with their pharmacist as excellent compared to only $40 \%$ of the elderly in Emirates of Dubai and Sharjah. The elderly with several disease conditions are more prone to taking several medications. Concerns about medication misuse are especially critical among older adults. Often, they are seen by more than one health-care provider, consume more prescription and non-prescription drugs, and have more complex medication regimens [17]. Taking numerous drugs together can stimulate interactions between drugs and could result in deterioration of the elderly health if not closely monitored. It is vital for prescribers to take extra care in persons aged over 60 years. About $54.26 \%$ of the elderly stated that they seek multiple prescribers to receive their medication. Pharmacists play a pivotal role in avoiding any potential drug-drug interaction, repeated regimen, or inappropriate selection of a medication. Asking the elderly to bring in all their medications and dietary supplements to the pharmacy every once in a while, could save the elderly from multiple prescriber's dilemmas $[17,18]$. A study of "brown bag" medication reviews, in which patients bring all their medications (often in a brown paper bag) to a medical or pharmacy consultation, revealed that $12 \%$

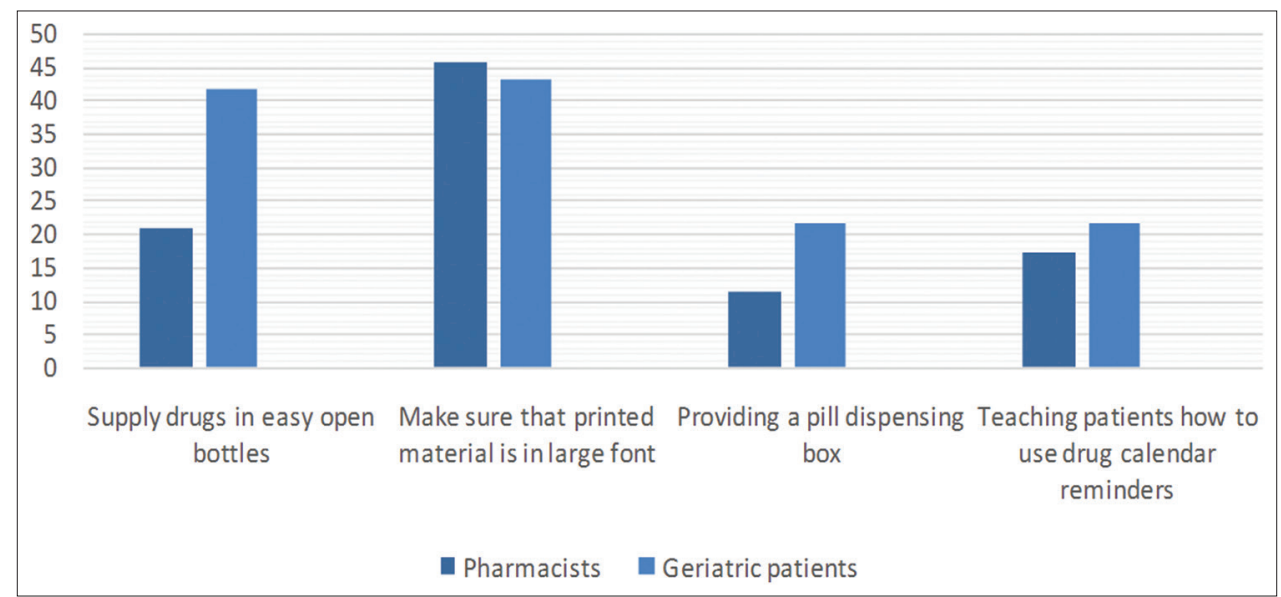

Fig. 2: Adherence techniques, what pharmacists offer and what geriatrics usually receive (\%) 
Table 3: Techniques offered to geriatrics by their pharmacists

\begin{tabular}{|c|c|c|}
\hline Answer & Percentage & Participants \\
\hline Supply drugs in easy open bottles & 42.0 & 29 \\
\hline $\begin{array}{l}\text { Make sure that printed material is } \\
\text { in large font }\end{array}$ & 43.5 & 30 \\
\hline Providing a pill dispensing box & 21.7 & 15 \\
\hline $\begin{array}{l}\text { Teaching patients how to use } \\
\text { drug calendar reminders }\end{array}$ & 21.7 & 15 \\
\hline $\begin{array}{l}\text { Teach you special techniques } \\
\text { about the use of certain } \\
\text { drugs (inhalers, patches.)? }\end{array}$ & 17.4 & 12 \\
\hline $\begin{array}{l}\text { Summarize all the instructions for } \\
\text { you at the end of your visit? }\end{array}$ & 39.1 & 27 \\
\hline
\end{tabular}

of the patients had medication problems that could potentially result in hospital admission [17]. A review of visits of patients 65 years and older found that $10.6 \%$ of the visits were related to an adverse drug event and 31\% had at least one potential adverse drug interaction in their medication regimen. Pharmacy reviews have demonstrated a reduction in polypharmacy in older adults and decreased adverse drug events in older patients [18].

An implementation of a "Medical Smart Card" for each patient, which contains all the details about the medications and dietary supplements that are prescribed by doctors and purchased, is a promising idea for this matter. All data present on the card could be accessed by any pharmacy and, hence, the pharmacist could check if there are any risks of multiple prescribers or polypharmacy. The same idea was introduced at 1994 in Europe where its aim was to increase the quality of health care for patients with chronic conditions. Portable Personal Medical Record on a smart card means that the necessary information of the patient is available at any time. Such communication tool will, thus, have an important impact on the quality of health care [19].

Compliance to a medication regimen was found to be achieved by $50 \%$ of the geriatrics who participated in the study. There are several reasons for elderly non-compliance; one that is worth casting a spot light on is the pharmacist role in assisting geriatrics to comply with their medications. The role of pharmacists in assisting geriatrics adhere to their drug regimen is very essential, represented by $45.74 \%$ of the elderly in this study who said that the pharmacist offers help concerning medication adherence. Several techniques were adopted by some pharmacists in the UAE to assist the elderly in medication adherence, such as supplying drugs in easy open bottles, making sure that printed material is in large font, providing a pillbox, and teaching patients how to use drug calendar reminders. The most commonly used technique was making sure that the printed material is in large font. Other studies have demonstrated that from $31 \%$ to $64 \%$ of older adults living at home have difficulty opening medication containers, in which childproof containers presented to be the most common difficulty [20]. The results of this study showed that supplying drugs in easy open bottles were the second most used technique by pharmacists to assist geriatrics in adhering to their medications. Adherence aids such as pill box organizers have been found to increase medication adherence, but according to our study, this technique was not extensively applied to geriatrics. Medication schedules and calendars are helpful, especially in combination with education and use of a pillbox, although this action was not as applicable in the UAE.

The pharmacist's attitude toward the elderly is very important for providing a high standard of medical care. It is essential that centered care is presented to geriatrics due to the biological and cognitive changes they undergo when they get older [21]. Most of pharmacists $(80.5 \%)$ who participated in the study said that they offer more counseling to the elderly compared to younger patients. About $71.65 \%$ of pharmacists think that the elderly find it hard to understand their instructions; this could be a reason why pharmacists counsel the elderly more than they would counsel younger patients.
Pharmacists require the knowledge, skills, and attitudes to meet the needs of the growing number of geriatrics in the UAE. Implementing a geriatric training course for pharmacists and pharmacy students in the UAE is a promising step for a high-quality geriatric care. An initial step to ensure that pharmacists are adequately prepared to care for a growing number of geriatric patients is to ensure that all pharmacy students receive a standardized training through a geriatric care course [22].

A variety of geriatric-related topics would be beneficial to include in a course designated to pharmacists willing to learn more about how to offer a proper pharmaceutical care to geriatrics in the UAE [22]. Such topics could include learning about the biological and cognitive changes that the elderly undergo, while learning how to offer a tailored counseling to this precise patient population and assisting them in adhering to medications while having chronic conditions. According to the study results, pharmacists of Dubai and Sharjah have higher interest to be enrolled in a geriatric training course to appropriately deal with elderly patients.

In 2012, the American Geriatric Society updated beers criteria for potential inappropriate medication use in older adults. The aim of the criteria was to improve the selection of prescription drugs by clinicians and patients, evaluate patterns of drug use within populations, educate clinicians and patients on proper drug usage, and assess health outcome, quality of care, cost, and utilization data [23].

In this study, benzodiazepines, pain killers, and antihistamines were chosen due to the high risk associated with their use by the elderly. Benzodiazepines can increase the risk of cognitive impairment, delirium, falls, fractures, and motor vehicle accidents. Because older adults have increased sensitivity to benzodiazepines and slower metabolism of longacting agents, so it is recommended that they should be avoided [23,24]. The most common group of medications that pharmacists were cautious about when dispensed to geriatrics is benzodiazepines which showed the highest percentage (62.5\%). Moreover, pain killers were the second group of medications that pharmacists were cautions about when dispensing to the elderly because they can increase the risk of indigestion, ulcers, and bleeding in stomach or colon. In addition to that, they can increase blood pressure, affect kidneys, and make heart failure worse. Accordingly, it is recommended to avoid chronic use of pain killers unless other alternatives are not effective. Furthermore, antihistamines are not recommended to be used in older patients because medication clearance is reduced with advanced age. Although antihistamines are sold without a prescription, they are not considered as a risk-free medication.

\section{Limitations}

Like all researches, this study had some limitations that were worth discussing. First of all, the sample size was relatively small to generalize our results to the whole geriatric population, taking into consideration that geriatrics was difficult to reach and several refused to respond to the survey questions. Besides that, some geriatrics patients do not visit the pharmacy by themselves; they send someone instead to get their medications. In addition, not all the emirates were included in the study. This study should be a base for a larger and more comprehensive study that can draw a more accurate conclusion.

\section{CONCLUSIONS}

Advanced health care has resulted in an increase life expectancy of the older adults in the UAE over the past years; this advancement has brought with it high expectations of the pharmaceutical care practiced in the UAE. Geriatric's satisfaction toward the pharmaceutical care provided was considered higher in the Emirate of Abu Dhabi compared to Dubai and Sharjah. Most of the geriatrics from Abu Dhabi described their relationship with their pharmacists as "Excellent." Compliance to medication regimen was found to be difficult in half of the geriatrics who participated in the study. In addition to that, multiple prescription rates were high which could result in a lot of medication-related problems that can be avoided through proper pharmacists' involvement. There 
is room for improving the pharmaceutical care in the UAE by providing a specialized training course about geriatrics to pharmacists and pharmacy students before graduation.

\section{ACKNOWLEDGMENTS}

The authors gratefully acknowledge Ms. Noor Kifah Al-Tameemi for her valuable help and support.

\section{AUTHORS' CONTRIBUTIONS}

All authors researched data and wrote the manuscript. All authors read and approved the final manuscript.

\section{DECLARATIONS}

\section{Funding}

Nil.

\section{Ethical approval}

This study was approved by University of Sharjah Research Ethics Committee.

\section{CONFLICTS OF INTEREST}

The authors declare that they have no conflicts of interest in this work.

\section{REFERENCES}

1. Care Plan for the UAE's ageing Population. The National; 2019 Available from: https://www.thenational.ae/uae/care-plan-for-the-uaes-ageing-population-1.397260. [Last accessed on 2019 Mar 14].

2. American society of hospital pharmacists. ASHP statement on pharmaceutical care. Medication Therapy and Patient Care: Organization and Delivery of Services Guidelines; 1993. p. 266-8.

3. Abe M, Agoboifo S, Singh H, Kashemsant P, Pabrai P, Davila R. The Role of Pharmacist in the Health Care System. Tokyo: World Health Organization; 1993. Available from: https://www.apps.who.int/iris/ handle/10665/59169. [Last accessed on 2019 Mar 14].

4. Zaman SS. Alzheimer's to rise $600 \%$ by 2030 in UAE; 2019. Available from: https://www.gulfnews.com/uae/health/alzheimers-to-rise-600by-2030-in-uae-1.1382654. [Last accessed on 2019 Mar 14].

5. 'Old Age is not an Illness': How Dubai's Care Centre is a Majlis for the Elderly. The National; 2019. Available from: https://www.thenational. ae/uae/health/old-age-is-not-an-illness-how-dubai-s-care-centre-is-amajlis-for-the-elderly-1.659947. [Last accessed on 2019 Mar 14].

6. Dha.Gov.ae; 2019. Available from: https://www.dha.gov.ae/ DHAOpenData/Statistical\%20Health\%20Publication/Health\%20 Profile\%20of\%202004.pdf. [Last accessed on 2019 Mar 14].

7. Shah AK. Compliance with medication among elderly people. Study of self medication on elderly people was flawed. BMJ 1995;311:259.

8. Chutka DS, Evans JM, Fleming KC, Mikkelson KG. Symposium on geriatrics - part I: Drug prescribing for elderly patients. Mayo Clin Proc 1995:70:685-93

9. Nash D, Koenig J, Chatterton M. Why the Elderly Need Individualized Pharmaceutical Care. Philadelphia, PA: Office of Health Policy and Clinical Outcomes Thomas Jefferson University; 2000. Available from: https:// www.researchgate.net/profile/Mary_Chatterton/publication/265141959 Why the Elderly Need Individualized Pharmaceutical Care/ links/55dd5d8c08ae591b309acf4d.pdf. [Last accessed on 2019 Mar 14].

10. Rochon PA, Gurwitz JH. Optimising drug treatment for elderly people: The prescribing cascade. BMJ 1997;315:1096-9.

11. Schmader KE, Hanlon JT, Pieper CF, Sloane R, Ruby CM, Twersky J, et al. Effects of geriatric evaluation and management on adverse drug reactions and suboptimal prescribing in the frail elderly. Am J Med 2004;116:394-401.

12. Is A. Polypharmacy: A risk factor for geriatric syndrome, morbidity and mortality. J Aging Sci 2013;1:2-4.

13. Corlett A. Caring for older people: Aids to compliance with medication. BMJ 1996;313:926-9.

14. Rantucci M. Counseling Geriatric Patients. Novopharm CE Compliance Centre National Continuing Education Program; 2004.

15. Elsaman RS, Mohamed AA. The rights of the elderly in the arab middle East: Islamic theory versus arabic practice. Marquette Elder's Advis 2012;14:1. Available from: https://www.papers.ssrn.com/sol3/papers. cfm?abstract id $=2196181$.

16. Haesler E, Bauer M, Nay R. Factors associated with constructive staff-family relationships in the care of older adults in the institutional setting. JBI Database Syst Rev Implement Rep 2016;4:1-72.

17. Lile JL, Hoffman R. Medication-taking by the frail elderly in two ethnic groups. Nurs Forum 1991;26:19-24.

18. Marek KD, Antle L. Medication Management of the Communitydwelling Older Adult. Rockville (MD): Agency for Healthcare Research and Quality (US); 2008.

19. Kühnel E, Klepser G, Engelbrecht R. Smart cards and their opportunities for controlling health information systems. Int $\mathrm{J}$ Biomed Comput 1994;35 Suppl:153-7.

20. Hughes R. Patient Safety and Quality: An Evidence-Based Handbook for Nurses. Rockville (MD): Agency for Healthcare Research and Quality (US); 2019.

21. Peters R. Ageing and the brain. Postgrad Med J 2006;82:84-8.

22. Augustine J, Shah A, Makadia N, Shah A, Iee JK. Knowledge and attitudes regarding geriatric care and training among student pharmacists. Curr Pharm Teach Learn 2014;6:226-32

23. American Geriatrics Society 2012 Beers Criteria Update Expert Panel. American geriatrics society updated beers criteria for potentially inappropriate medication use in older adults. J Am Geriatr Soc 2012;60:616-31.

24. Damron-Rodriguez J, Kramer BJ, Gallagher-Thompson D. Effect of geriatric clinical rotations on health professions trainees' attitudes about older adults. Gerontol Geriatr Educ 1998;19:67-79. 